\title{
PREPARATION AND SPECTROSCOPY OF LANTHANIDE SINGLE CRYSTALS WITH ISOLEUCINE
}

\author{
J. Legendziewicz, Z. CiUniK, P. GaWryszewska and J. Sokolnicki \\ Institute of Chemistry, University of Wrocław \\ F. Joliot-Curie 14, 53-338 Wroclaw, Poland
}

Single crystals of lanthanide complexes $(\mathrm{Ln}=\mathrm{Pr}, \mathrm{Nd}, \mathrm{Eu})$ were obtained from aqueous solutions. Optical properties of the title compound are investigated by absorption, excitation, and emission spectra. Probabilities of electronic transitions were analysed and participation of vibronic components in the spectra were found. Temperature effect on the spectra was studied and analysed in terms of cooperative interaction.

PACS numbers: $78.20 \mathrm{Wc}$; $78.55 \mathrm{Hx}$

\section{Introduction}

Recently we have reported the spectroscopic and crystal structure data of series of lanthanide polymeric and dimeric complex compounds with amino acids and peptides which can be considered as a model of systems of biological interest [1-4].

The effect of ligand chirality on the structure and influence of polymeric and dimeric structures on spectroscopic properties of investigated systems was found $[1,2]$.

Now, we present the spectroscopic and structure data of lanthanide dimeric single crystals with L-isoleucine as second example of dimeric compound. The problems which we wanted to solve are the following:

a) the influence of the ligand structure on $\mathrm{Me}-\mathrm{L}$ bonding length;

b) the confirmation of ligand chirality on creation of non-centrosymmetric dimeric units and its spectroscopic consequences;

c) the confirmation of the effects of dimeric structure on the broadening of optical lines;

d) the participation of cooperative interaction in dimeric structure and vibronic coupling in electronic lines. 


\section{Experimental}

Single crystals of title compounds were obtained from $\mathrm{Ln}\left(\mathrm{ClO}_{4}\right)_{3}$ water solution at $\mathrm{pH} \approx 3.5$ where the concentration of $\mathrm{L}$-isoleucine was below $\mathrm{Ln}^{3+}$ concentration [5]. X-ray results were collected using a KUMA diffractometer. Absorption spectra at 5 and $300 \mathrm{~K}$ were recorded on the Cary-Varian spectrophotometer. AMINCO SPF-500 spectrofluorometer was used for the luminescence and excitation spectra detection at $77 \mathrm{~K}$.

\section{Results and discussion}

Selected Me-L and Ln-Ln distances are presented in Table I. Crystal structure data indicate the creation of non-centrosymmetric dimers with two nonequivalent lanthanide ions positions and coordination number $=8$ (Fig. 1). The coordination polyhedron can be described as close to the square antiprism. The

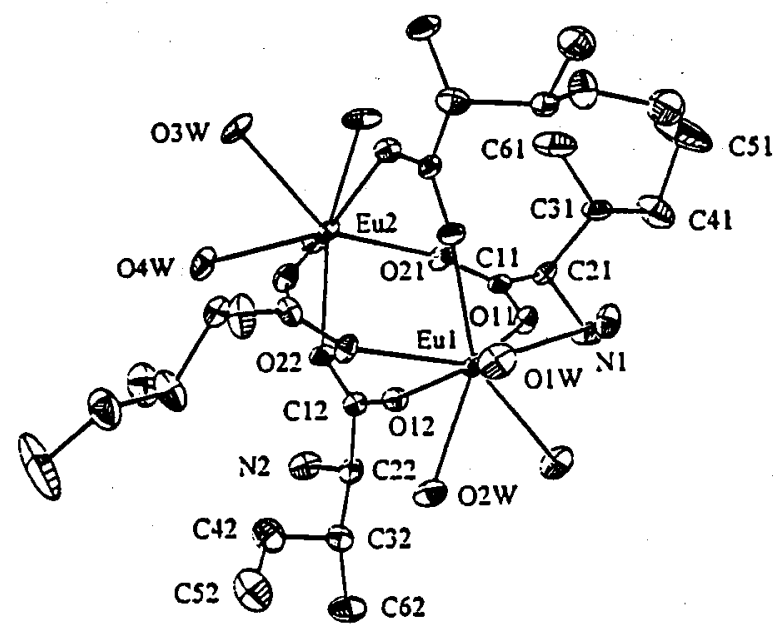

Fig. 1. Crystal structure of the $\left[\mathrm{Eu}(\mathrm{L}-\mathrm{Ile})_{2}\left(\mathrm{H}_{2} \mathrm{O}\right)_{4}\right]_{2} \cdot\left(\mathrm{ClO}_{4}\right)_{6}$.

TABLE I

The bond lengths of $\left[\mathrm{Eu}(\mathrm{L}-\mathrm{Ile})_{2}\left(\mathrm{H}_{2} \mathrm{O}\right)_{4}\right]_{2} \cdot\left(\mathrm{ClO}_{4}\right)_{6}$ single crystal $[\AA]$.

\begin{tabular}{l|l|l|l}
\hline \hline Eu1-Eu2 & 4.479 & & \\
Eu1-O(1w) & 2.459 & Eu2-O(3w) & 2.626 \\
Eu1-O(2w) & 2.473 & Eu2-O(4w) & 2.561 \\
Eu1-O(11) & 2.477 & Eu2-O(21) & 2.329 \\
Eu1-O(12) & 2.370 & Eu2-O(22) & 2.451
\end{tabular}


isoleucine branching chain results in lengthening the Me-L bonds compared to those observed in complexes with L-alanine [6], which should be reflected in intensity of hypersensitive transition. Tables II and III collect the oscillator strength values at 300 and $5 \mathrm{~K}$ for neodymium and praseodymium single crystals and the Judd-Ofelt parameters calculated using the ICM programme $[7,8]$. The intensi-

TABLE II

The oscillator strength values of $f-f$ transitions of the $\left[\mathrm{Nd}(\mathrm{L}-\mathrm{Ile})_{2}\left(\mathrm{H}_{2} \mathrm{O}\right)_{4}\right]_{2} \cdot\left(\mathrm{ClO}_{4}\right)_{6}$ single crystal.

\begin{tabular}{c|l|c|c}
\hline \hline $\begin{array}{c}\text { Spectral region } \\
{[\AA]}\end{array}$ & \multicolumn{1}{|c|}{$S^{\prime} L^{\prime} J^{\prime}$} & \multicolumn{2}{|c}{$P_{\exp } \times 10^{8}$} \\
\cline { 2 - 4 } & & $T=295 \mathrm{~K}$ & $T=5 \mathrm{~K}$ \\
\hline $8450-9100$ & ${ }^{4} F_{3 / 2}$ & 968.02 & - \\
$7742-8450$ & ${ }^{4} F_{5 / 2},{ }^{2} H_{9 / 2}$ & 988.95 & - \\
$7050-7742$ & ${ }^{4} F_{7 / 2},{ }^{4} S_{3 / 2}$ & 58.55 & - \\
$6600-7050$ & ${ }^{4} F_{9 / 2}$ & - & 32.59 \\
$6100-6600$ & ${ }^{2} H_{11 / 2}$ & 1103.41 & 952.85 \\
$5500-6100$ & ${ }^{4} G_{5 / 2},{ }^{2} G_{7 / 2}$ & 651.82 & 371.08 \\
$4900-5500$ & ${ }^{2} K_{13 / 2},{ }^{4} G_{7 / 2},{ }^{4} G_{9 / 2}$ & & \\
$4450-4950$ & ${ }^{2} K_{15 / 2},{ }^{2} G_{9 / 2}$, & 192.51 & - \\
& $\left({ }^{2} D,{ }^{2} F\right)_{3 / 2},{ }^{4} G_{11 / 2}$ & 40.88 & - \\
$4150-4400$ & ${ }^{2} P_{1 / 2},{ }^{2} D_{5 / 2}$ & & - \\
$3385-3700$ & ${ }^{4} D_{3 / 2},{ }^{4} D_{5 / 2},{ }^{2} I_{11 / 2}$ & & \\
& ${ }^{4} D_{1 / 2},{ }^{2} L_{15 / 2}$ & 911.88 & - \\
$3200-3385$ & ${ }^{2} I_{13 / 2},{ }^{4} D_{7 / 2},{ }^{2} L_{17 / 2}$ & 227.26 & - \\
\hline
\end{tabular}

TABLE III

The oscillator strength values of $f-f$ transitions of the $\left[\mathrm{Pr}(\mathrm{L}-\mathrm{Ile})_{2}\left(\mathrm{H}_{2} \mathrm{O}\right)_{4}\right]_{2} \cdot\left(\mathrm{ClO}_{4}\right)_{6}$ single crystal.

\begin{tabular}{c|l|c}
\hline \hline Spectral region $[\AA]$ & \multicolumn{1}{|c}{$S^{\prime} L^{\prime} J^{\prime}$} & $P_{\exp } \times 10^{8}(293 \mathrm{~K})$ \\
\hline $4280-4580$ & ${ }^{3} H_{4} \rightarrow{ }^{3} P_{2}$ & 1653.70 \\
$4580-4790$ & ${ }^{3} H_{4} \rightarrow{ }^{3} P_{1},{ }^{1} I_{6}$ & 597.53 \\
$4790-5000$ & ${ }^{3} H_{4} \rightarrow{ }^{3} P_{0}$ & 180.32 \\
$5650-7000$ & ${ }^{3} H_{4} \rightarrow{ }^{1} D_{2}$ & 481.51
\end{tabular}

ties of optical lines connected with hypersensitive transition confronted with the intensities of the respective transition observed in single crystals of $L$-alanine complex compounds are decreased by lowering of $\mathrm{Ln}-\mathrm{O}$ bond lengths ( $\mathrm{L}-\mathrm{isoleucine}$; 
$\mathrm{Eu}_{2 \text { mean }}=2.491, \mathrm{Eu}_{1 \text { mean }}=2.445, \mathrm{~L}-\alpha$-alanine; $\left.\mathrm{Eu}_{1 \text { mean }}=2.415\right)$. This effect was found in the Nd spectra.

Judging from the decrease in intensity at $5 \mathrm{~K}$ the vibronic coupling manifests in the intensity of spectral lines (see Fig. 2 and Table II). Moreover, this effect

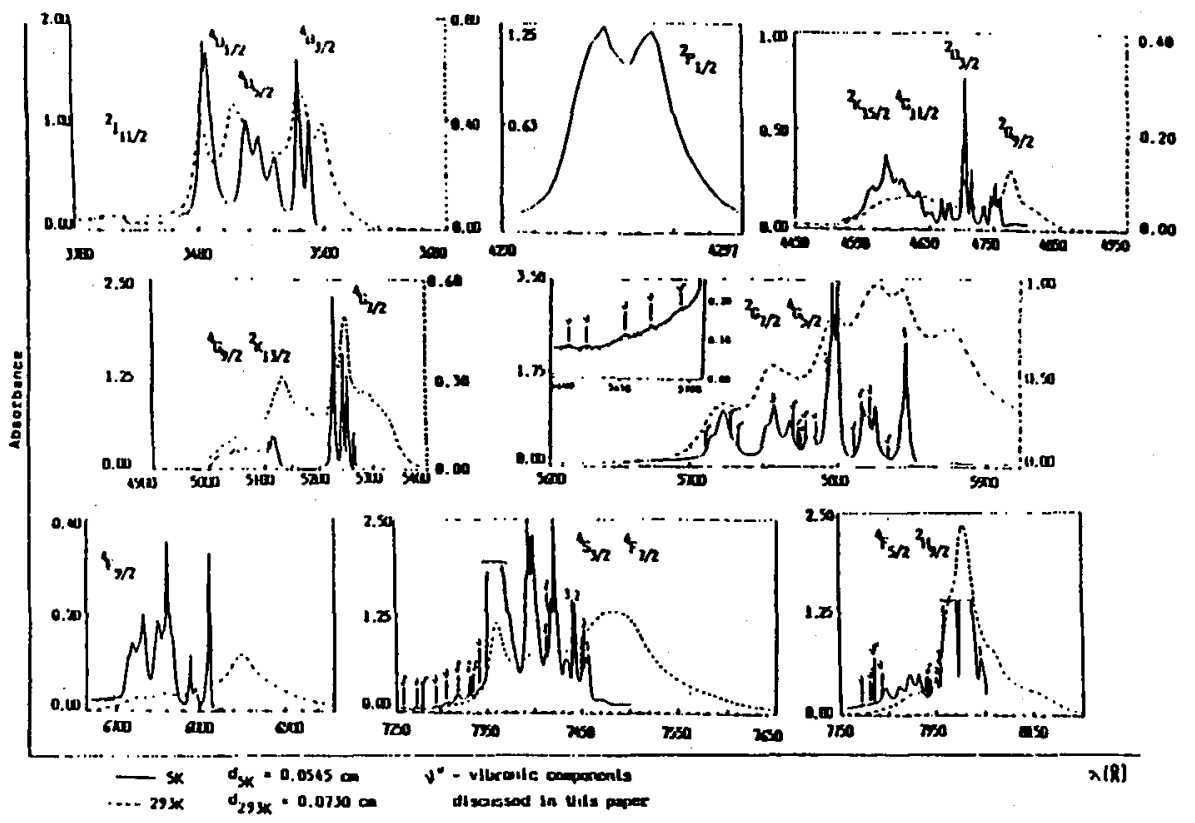

Fig. 2. Absorption spectra of the $\left[\mathrm{Nd}(\mathrm{L}-\mathrm{Ile})_{2}\left(\mathrm{H}_{2} \mathrm{O}\right)_{4}\right]_{2} \cdot\left(\mathrm{ClO}_{4}\right)_{6}$ single crystal at $5 \mathrm{~K}$ and $293 \mathrm{~K}$.

is quite well demonstrated in the complex structure of absorption and emission bands at low temperatures. Figures 2 and 3 show electronic spectra at 300, 77 and $5 \mathrm{~K}$. The complex structure of the bands observed in the absorption, emission, and excitation spectra mainly of those related to the transitions which obey the selection rule $|\Delta J|=2.0$ is striking. Besides weak components of main lines, the significant broadening of electronic lines is observed (see Fig. 2).

The weak sidebands result from vibronic coupling whose intensity, according to the theoretical model given by Judd [9], Dexpert-Ghys and Auzel [10], and Stavola [11], depend on the matrix elements $\left\langle\left\|U^{(2)}\right\|\right\rangle$ of the respective electronic transition. According to the Blasse et al. consideration it can be described as follows [9]:

$$
P_{\nu} \approx \nu\left(g+n \alpha R^{-3}\right)^{2} \Xi(1,2)^{2}\left\langle J\left\|U^{(2)}\right\| J^{\prime}\right\rangle^{2}[1 /(2 J+1)]\left\langle 0\left\|T^{(1)}\right\| p\right\rangle^{2},
$$

where $P_{\nu}$ is the oscillator strength of the vibronic transition involved, $\nu-$ its frequency, $n$ is the number of ligand around Me, $g$ and $\alpha$ are the charge and polarizability of the ligand, $R$ is the Me-ligand distance, $\Xi(1,2)$ is defined by Judd [7] and connected with the opposite-parity configuration mixing, $J$ and $J^{\prime}$ are the total quantum numbers of the initial and final electronic states. $\left\langle\left\|U^{(2)}\right\|\right\rangle$ 
is the matrix element of the reduced tensor operator and $\left\langle\left\|T^{(1)}\right\|\right\rangle$ is the matrix element of the electric dipole operator of $(0)$ and $(p)$ vibrational states.

Since the vibronic components belong to the electronic transitions with different $\left\langle\left\|U^{(2)}\right\|\right\rangle$ matrix elements, the intensities observed in the luminescence excitation and absorption spectra are different (see Figs. 2, 3).

Assignments of the vibronic components are given in Table IV. Only those vibration modes are considered which were found in composition of vibration mode with different Stark components for given electronic transition and from absorption and excitation $\mathrm{Eu}^{3+}$ spectra.

Moreover, judging from $\mathrm{X}$-ray analysis (Nd-Nd distances in Table I) one can expect the ion-pairs interaction and its effect on optical lines. In fact, the low temperature spectra indicate both broadening of the electronic lines and relatively strong additional components easily observed in the ${ }^{4} I_{9 / 2} \rightarrow{ }^{2} P_{1 / 2}$ transition at $5 \mathrm{~K}$ and additional components in many electronic lines whose number exceeds the number of lines for two nonequivalent $\mathrm{Ln}$ ions position in the structure.

The cooperative interaction in praseodymium and neodymium ionic compounds was investigated by Vial and Buisson [13], Malinowski and Stręk [14]. They explain it by exchange or multiple interactions in the excited states. Those additional components observed by us are results of the exchange, multipole or phonon mediated interactions in the excited states.

At this moment of investigation it is difficult to say which mechanism is predominating.

Confirmation of Ln-Ln interaction was found by us [15] in similar polymeric lanthanide systems by EPR investigation.

Comparison of spectroscopic results of the data presented here with those reported earlier [1,2] indicates the same order of broadening of the optical lines in both systems, confirming the influence of dimeric structures of investigated compound on its spectroscopic properties.

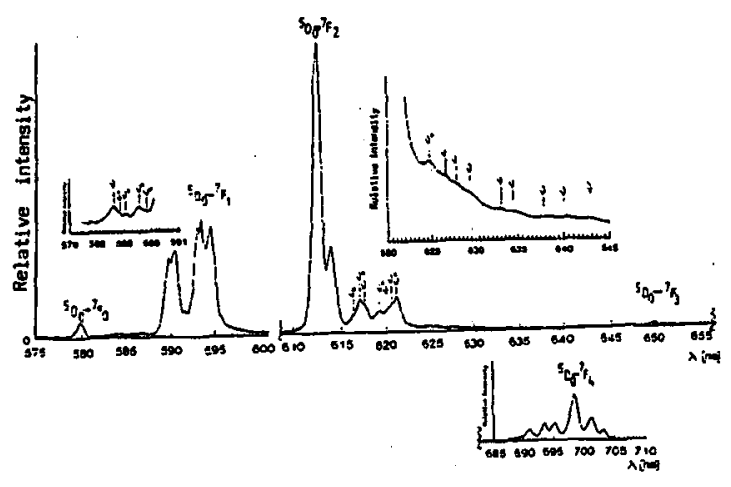

Fig. 3. Fluorescence spectrum of the $\left[\mathrm{Eu}(\mathrm{L}-\mathrm{Ile})_{2}\left(\mathrm{H}_{2} \mathrm{O}\right)_{4}\right]_{2} \cdot\left(\mathrm{ClO}_{4}\right)_{6}$ single crystal at $77 \mathrm{~K}$. 
TABLE IV

Vibronic components in absorption spectra of $\left[\mathrm{Nd}\left(\mathrm{L}-\Pi_{\mathrm{e}}\right)_{2}\left(\mathrm{H}_{2} \mathrm{O}\right)_{4}\right]_{2} \cdot\left(\mathrm{ClO}_{4}\right)_{6}$ $(T=5 \mathrm{~K})(\mathrm{a})$ and vibronic components in luminescence and excitation spectra of $\left[\mathrm{Eu}(\mathrm{L}-\mathrm{Ile})_{2}\left(\mathrm{H}_{2} \mathrm{O}\right)_{4}\right]_{2} \cdot\left(\mathrm{ClO}_{4}\right)_{6}(T=77 \mathrm{~K})(\mathrm{b})$.

\begin{tabular}{|c|c|c|c|}
\hline \multicolumn{4}{|l|}{ (a) } \\
\hline Transition & $\begin{array}{l}\text { Energy } \\
{\left[\mathrm{cm}^{-1}\right]}\end{array}$ & \multicolumn{2}{|c|}{$\begin{array}{c}\Delta E \text { (from 0-phonon line) } \\
{\left[\mathrm{cm}^{-1}\right]}\end{array}$} \\
\hline \multirow[t]{7}{*}{${ }^{4} I_{9 / 2} \rightarrow{ }^{2} H_{9 / 2},{ }^{4} F_{5 / 2}$} & 1. 12458 & \multirow{4}{*}{$\left.\begin{array}{c}103 \\
136 \\
161 \\
336\end{array}\right\}$} & \multirow[b]{2}{*}{$r(\mathrm{Ln}-\mathrm{OCO}-\mathrm{Ln})$} \\
\hline & 12561 & & \\
\hline & 12594 & & $\delta(O-\operatorname{Ln}-0)$ \\
\hline & 12794 & & $\delta(\mathrm{COO})$ \\
\hline & 2. 12575 & \multirow[b]{2}{*}{30} & \\
\hline & 12605 & & $\tau(\mathrm{Ln}-\mathrm{OCO}-\mathrm{Ln})$ \\
\hline & 12778 & 203 & $\delta(\mathrm{OLnO})$ \\
\hline \multirow[t]{15}{*}{${ }^{4} I_{9 / 2} \rightarrow{ }^{4} S_{3 / 2},{ }^{4} F_{7 / 2}$} & 1. 13394 & \multirow[b]{2}{*}{$32)$} & \multirow[b]{3}{*}{$\tau(\mathrm{Ln}-\mathrm{OCO}-\mathrm{Ln})$} \\
\hline & 13426 & & \\
\hline & 13485 & $91\}$ & \\
\hline & 13628 & 234 & $\nu(\mathrm{NdO})$ \\
\hline & 13737 & 343 & $\delta(\mathrm{COO})$ \\
\hline & 2. 13437 & & \\
\hline & 13476 & 39 & $\tau(\mathrm{Ln}-\mathrm{OCO}-\mathrm{Ln})$ \\
\hline & 13639 & 202 & $\delta(\mathrm{OLnO})$ \\
\hline & 13664 & 227 & $\nu(\mathrm{NdO})$ \\
\hline & 13783 & 346 & $\delta(\mathrm{COO})$ \\
\hline & 3. 13441 & & \\
\hline & 13476 & 35 & $\tau(\mathrm{Ln}-\mathrm{OCO}-\mathrm{Ln})$ \\
\hline & 13645 & 204 & $\delta(\mathrm{OLnO})$ \\
\hline & 13664 & 223 & $\nu(\mathrm{NdO})$ \\
\hline & 13783 & 342 & $\delta(\mathrm{COO})$ \\
\hline \multirow[t]{14}{*}{${ }^{4} I_{3 / 2} \rightarrow{ }^{2} G_{7 / 2},{ }^{4} G_{5 / 2}$} & 1. 17106 & \multirow[b]{2}{*}{35 ) } & \multirow{4}{*}{$\tau(\mathrm{Ln}-\mathrm{OCO}-\mathrm{Ln})$} \\
\hline & 17141 & & \\
\hline & 17194 & $88\}$ & \\
\hline & 17203 & 97 & \\
\hline & $\begin{array}{l}17268 \\
17307\end{array}$ & $\left.\begin{array}{l}162 \\
201\end{array}\right\}$ & $\delta(\mathrm{OLnO})$ \\
\hline & 17334 & 228 & $\nu(\mathrm{LnO})$ \\
\hline & 17449 & 343 & $\delta(\mathrm{COO})$ \\
\hline & 2. 17244 & & \\
\hline & 17328 & 84 & $\tau(\mathrm{Ln}-\mathrm{OCO}-\mathrm{Ln})$ \\
\hline & 17449 & 205 & $\delta(\mathrm{OLnO})$ \\
\hline & 17464 & 220 & $\nu(\mathrm{NdO})$ \\
\hline & 3. 17372 & & \\
\hline & 17464 & & $\tau(\mathrm{Ln}-\mathrm{OCO}-\mathrm{Ln})$ \\
\hline & $\begin{array}{l}17510 \\
17578\end{array}$ & $\left.\begin{array}{l}138 \\
206\end{array}\right\}$ & $\delta(\mathrm{OLnO})$ \\
\hline
\end{tabular}




\begin{tabular}{l|r|c|c}
\hline \hline (b) & \multicolumn{2}{|c}{$\Delta E$ (from 0-phonon line) } \\
{$\left[\mathrm{cm}^{-1}\right]$}
\end{tabular}

\section{References}

[1] J. Legendziewicz, E. Huskowska, W. Ryba-Romanowski, A. Kozanecki, in: Excited States of Transition Elements, Eds. W. Stręk, W. Ryba-Romanowski, I. Legendziewicz, B. Jeżowska-Trzebiatowska, World Sci., Singapore 1992, p. 367.

[2] J. Legendziewicz, in Ref. [1], p. 149.

[3] I. Csöregh, J. Legendziewicz, E. Huskowska, Acta Crystallogr. C 48, 1030 (1992).

[4] T. Glowiak, E. Huskowska, J. Legendziewicz, Polyhedron 11, 289 (1992).

[5] J. Legendziewicz, E. Huskowska, A. Waśkowska, Gy. Argay, Inorg. Chim. Acta 92, 151 (1984).

[6] J. Legendziewicz, T. Głowiak, E. Huskowska; C.N. Dao, in: Rare Earth Spectroscopy, Eds. B. Jeżowska-Trzebiatowska, I. Legendziewicz, W. Stręk, World Sci., Singapore 1985, p. 146.

[7] B.R. Judd, Phys. Rev. 127, 750 (1962).

[8] J. Legendziewicz, Bull. Pol. Acad. Chem. 7-8, 56 (1985).

[9] B.R. Judd, Phys. Scr. 21, 543 (1980).

[10] J. Dexpert-Ghys, F. Auzel, J. Chem. Phys. 80, 4003 (1984).

[11] M. Stavola, L. Isganitis, M.G. Sceats, J. Chem. Phys. 74, 4228 (1981).

[12] G. Blasse, Inorg. Chim. Acta 167, 33 (1990).

[13] J.C. Vial, R. Buisson, J. Phys. Lett. (France) 43, L-745 (1982).

[14] M. Malinowski, W. Stręk, J. Phys. C, Solid State Phys. 20, 2595 (1987).

[15] Y. Yablokov, J. Legendziewicz, unpublished results. 